\title{
El deporte en la educación física escolar. La revisión histórica de una crítica inacabada Sport in school physical education. Historical review of an unfinished critique \\ *Xavier Torrebadella-Flix, **JoséAntonio Domínguez Montes \\ *Universidad Autónoma de Barcelona (España), **I.E.S. Ramón y Cajal, Tocina (España)
}

Resumen. El deporte apareció como un nuevo sistema de educación física, creando y configurando su propia escuela y enfrentándose a las tres grandes escuelas o tendencias gimnásticas dominantes en la Europa del siglo XIX. El presente artículo de corte histórico, plantea los posicionamientos entre defensores y detractores del deporte, en relación a la educación física escolar; se expone y desarrolla una revisión histórica y crítica la cual se diría que está inacabada. Para dar alcance al objeto de estudio suscitado, nos apoyamos en la metodología heurística, basada principalmente en la búsqueda de fuentes documentales primarias, donde gran parte de la indagación documental se ha obtenido de la revisión y del análisis crítico en torno a las obras originales del período histórico comprendido entre finales del siglo XIX y el primer tercio del siglo XX. Renombrados especialistas en la materia, posicionados como partidarios y detractores exponen sus ideas y justifican su tesis a través de aportaciones de gran peso y calado histórico, hasta el punto de que hoy día este espacio de controversia didáctica y pedagógica perdura entre los docentes en el marco de la educación física escolar.

Palabras clave. Deporte, educación física escolar, defensores, detractores.

Abstract. Sport appeared as a new system of physical education, creating and forming its own school and facing three big schools or gymnastic dominant trends in $19^{\text {th }}$-century Europe. The present article raises the positioning between defenders and detractors of sport in relation to school physical education; exposing and developing a historical and critical review which might be seen as unfinished. We used heuristic methodology based on the search of documented primary sources, which constituted a great part for the review and critical analysis concerning original works of the historical period between the end of 19th century and the first third of the 20th century. Renowned specialists in this matter, positioned as supporters and detractors, exposed their ideas justifying their theory by using contributions of great weight and historical importance up to the current state outlining the prolonged didactic and pedagogic controversy among teachers in the framework of school physical education.

Keywords. Sport, physical education school, defenders, detractors.

\section{Introducción}

A mediados del siglo XIX en España la palabra inglesa sport, en el sentido moderno (de deporte), ya se encontraba presente para identificar las aficiones a los juegos corporales y a las carreras de caballos de la cultura anglosajona (Olivera-Betrán \& Torrebadella-Flix, 2015).Amedida que avanzaba el siglo, el sport inglés era asimilado en las costumbres recreativas de la alta sociedad. Las noticias internacionales en prensa y revistas divulgan los elitistas usos del sport, y como la elegante sociedad europea y americana entraba en las nuevas e higiénicas diversiones de emulación. Puede decirse que en este tipo de prácticas nacía un moderno postureo, que construía los habitus de distinción de una sociedad liberal que se lanzaba ambiciosa a las conquistas y placeres.

En España el sport tuvo que rivalizar con los juegos populares, como por ejemplo el juego del marro (Brasó \& Torrebadella, 2015a, 2015b) y los llamados deportes nacionales, como los toros y el juego de pelota. Muchos de estos juegos fueron perdiendo significación social entre las clases cultivadas (Olavarrieta, 1930) y quedaron desatendidos al pasar a meros pasatiempos del vulgo. Por otro lado, otras prácticas recreativas e higiénicas, de la entonces gimnástica, sufrieron un proceso de socialización e institucionalización deportiva. Nos referimos a las prácticas como el juego de pelota, la esgrima, la equitación, las regatas de botes, la caza, el tiro al pichón, el baile, las carreras pedestres, los lanzamientos, los juegos regionales de lucha..

Este proceso fue coincidente con los cambios urbanísticos de las principales ciudades españolas: derribo de las murallas, apertura de ensanches y de plazas, paseos, parques, oxigenación de las zonas insalubres, salidas hacia extramuros del casco viejo... Con lo cual, la población volvía a ‘deportarse’ (de puertas a fuera) al deporte, es decir, a la recreación al aire libre. Paradójicamente, mientras llegaba la mano de obra procedente del campo para ocupar puestos de trabajo en las industrias urbanas, las clases acomodadas huían de la masificación humana y de los focos de insalubridad en busca saludables zonas residenciales en el campo o litoral, con lo cual podían ocupar el tiempo libre en recreaciones campestres (natación y baños de mar, caza y pesca, equitación, paseos y excursiones, deportes náuticos...).

De aquí surgía una pedagogía física que desde la infancia hasta la

Fecha recepción: 07-05-17. Fecha de aceptación: 02-12-17

José Antonio Domínguez Montes

jadmef03@hotmail.com edad adulta reglamentaba las prácticas corporales recreativas. La confluencia de liberalismo y romanticismo movilizó una elitista juventud estudiantil a la búsqueda de placeres y diversiones, es decir, a todo tipo de excitaciones corporales, de cultos y ritos de virilidad y de formas de distinción de clase. Aquí, los sports, para muchos aún conceptuados como prácticas gimnásticas, se presentaban a satisfacer toda una moderna figuración social. Nacía pues, la industria de una nueva recreación, de condición saludable y moralizante, que entraba de lleno como alternativa civilizada y opuesta a las reprobadas conductas viciosas que tanta aceptación tenían en la juventud. Por lo tanto, teatros, salas de baile, gimnasios, salones de recreo, tabernas, casas de juegos, prostíbulos, ... configuraban las opciones a elegir.

La sociedad europea del siglo XIX creció amenazada por los miedos que suscitaban las tesis del degeneracionismo biológico, es decir sobre la degeneración de la especie. Como cita Barbero (1996, p. 16), el mismo origen de la educación física escolar apareció «asociado a los temores sobre la degeneración de la raza y el stock físico de la nacionesestado, industriales». El renacer neoclásico del culto al cuerpo puso en la órbita pedagógica y de la escolarización la educación física. En este nuevo campo de la escolarización del cuerpo, la gimnástica y el gimnasio popularizaron un nuevo concepto del ejercicio físico, alejado de las prácticas funambulescas. Sobre esta percepción, nacía también el mito del «hombre nuevo»; una idealización intelectualizada que en determinados círculos ideológicos sirvió para legitimar los discursos de la regeneración social. En este ideal se fraguó el discurso regeneracionista de la Institución Libre de Enseñanza (ILE), que encontró su máxima expresión a raíz de la crisis finisecular (Torrebadella-Flix, Olivera-Betrán, \& M-Bou, 2015).

Digamos, en un principio, que las proyecciones de los miedos sociales a la degeneración humana argumentaron las principales razones que movilizaron el renacer de las prácticas gimnásticas y de la educación física escolar. En esta coyuntura se dirigió la mirada a Inglaterra, nación que despuntaba como gran potencia mundial, y el prestigio de sus instituciones educativas-las Public Schools-que se presentaban como el paradigma a seguir. Como es bien conocido, es en estos colegios ingleses en donde el deporte entró y conformó la piedra angular de la educación victoriana.

Cuando los diferentes sistemas de gimnástica (o de educación física) concurrían a disputarse la eficacia y la supremacía técnica («guerra de sistemas»), es decir los métodos gimnásticos creados por el valenciano Francisco Amorós, que se desarrollaba en Francia y España; el de Pehr 
Henrik Ling en Suecia y el de Friedrich Ludwig Jahn en Prusia, en Inglaterra, los llamados juegos corporales (o sport) iban conquistando las simpatías de jóvenes de todo el mundo. A la sazón, el movimiento pedagógico del deporte anglosajón encontró el estímulo en los reformadores franceses, en especial a Pierre de Coubertin, Paschal Grousset y Georges de Saint-Clair y Philippe Tissié, quienes no dudaron en proclamar las excelencias de la educación inglesa, situación que culminó con el movimiento atlético internacional que llevó en 1896 a la restauración de los JJOO. Como es conocido, al finalizar la Primera Guerra Mundial el deporte alcanzó un prominente protagonismo (Torrebadella, 2016b). Como citaba el Dr. Philippe Tissié (1852-1935) -toda una autoridad en la educación física-, a partir de entonces el deporte entró a configurar una nueva forma de participar en las estrategias de dominación y en las guerras económicas del mundo (Tissié, 1919).

Si en el caso concreto de España, el deporte fue un proceso de configuración débil y lento (Torrebadella-Flix, Olivera-Betrán, \& MBou, 2015), su comparación con otros países occidentales, que desde 1896 se habían consagrado al movimiento olímpico internacional, es muy significativa, aunque particularmente matizable al tratar las excepciones del ciclismo y el fútbol. Este último alcanzó un rápido desarrollo (Torrebadella-Flix, Olivera-Betrán, \& M-Bou, 2017), especialmente a partir de su aceptación pedagógica y recreativa en los colegios de las congregaciones religiosas, que era donde se educaban los jóvenes de las clases pudientes(Torrebadella, 2017; Torrebadella-Flix \& Vicente-Pedraz, 2017). No fue así en los colegios públicos, en los cuales ni siquiera la gimnasia tenía acto de presencia.

En los discursos de la «guerra de sistemas» de la educación física, la idoneidad científica (higiénica) y pedagógica de los juegos tradicionales (juegos nacionales), las gimnásticas (propiamente dichas) y el deporte, originaron reveladoras disputas doctrinales y de sectas nacionales (Soler, 1936). En estas disputas (inútiles y perniciosas) la problematización acerca del deporte inició en el campo de la educación física una de las polémicas más genuinas y emblemáticas que se conocen. Como en el pasado, hoy siguen poniéndose en duda los bienes higiénicos del deporte para la salud y, todavía más, sus controvertidos y supuestos valores educativos.

De aquí parte el presente artículo de corte histórico, que revisa y expone el concepto de deporte en toda su potencialidad, versatilidad y gama de matices, donde finalmente se justifican las propuestas que hacen partidarios y detractores del mismo. Es, por lo tanto, y en relación a lo argumentado, que se recupera y se replantea la disyuntiva que, desde el pasado, subyace en la misma razón de ser del deporte, con lo cual se reproduce y se renueva, en los regímenes de la escolarización de la educación física para la primera y segunda enseñanza.

La metodología utilizada tiende, a partir de la revisión bibliográfica de la época y de otras fuentes secundarias (Torrebadella-Flix, 2017b), a construir una interpretación socio-crítica del currículo actual de la educación física, con lo cual se evidencian las divergencias y conciencias del pasado con el presente. Sobre esta formulación, se comprueba que la presencia inicial del deporte moderno provocó una «crisis» ideológica y técnica en la comprensión epistemológica de la educación física en España. Este conflicto tuvo un proceso de configuración, cuya cronológica estuvo marcada por las vicisitudes del entorno educativo y social del momento histórico.

\section{Partidarios y detractores del deporte}

Olivera-Betrán y Torrebadella-Flix (2015) presentan las primeras definiciones modernas de deporte que vienen a concretar otros destacados estudios anteriores (Fernández, 1971; Piernavieja, 1966, Trapero, 1994; Wagner, 1970). Entre estas definiciones hay que señalar aquellas que a finales del siglo XIX se adentraban en esclarecer la complejidad del campo semántico. Aun así, hay que incidir que la acepción del término deporte, como uso técnico, tardaría varias décadas en ser admitida en los diccionarios en uso y de la RAE. Una de las primeras definiciones fue la del Dr. García Fraguas (1897):
El sport o deporte, es todo conjunto de ejercicios físicos reglamentados y practicados con el fin de adiestrarse para un recreo u entretenimiento al servicio de la vanidad o de la actividad física personal, sin preocuparse de sus consecuencias ni utilidad social, como ocurre con el baile, la equitación, el ciclismo, el canotage, los zancos, patines, trineos, el boxeo, la esgrima, la caza, el tiro al blanco, el acrobatismo gimnástico de los establecimientos industriales, etc., etc. (Fraguas, 1897, p. 2).

Desde entonces, como indican Olivera-Betrán y Torrebadella-Flix (2015), las definiciones de la palabra han llenado las páginas de la literatura deportiva y algunos autores han procurado desvincularla de la educación física.

Es conocido que la ILE apadrinó los juegos corporales adscritos al modelo educativo inglés, tanto desde la educación física, como de la recreación de los mismos juegos (López Serra, 1998). Alejandro San Martín (1889) mencionaba que la ILE, desde 1878 ya procuraba el establecer los juegos corporales en sus colegios, una posición que se presentaba como la alternativa al sistema de educación física preconizado por Francisco Amorós y del que la Escuela Central de Gimnástica (1887-1892), establecida en Madrid, ponía en uso con el objeto de formar al profesorado titular de Gimnástica que había de impartir esta asignatura en los institutos de segunda enseñanza. Sin embargo, las directrices pedagógicas que recibió el profesorado de dicha enseñanza, por parte de la Dirección General de Instrucción Pública, se orientaron hacia el modelo de los juegos corporales, así ya sucedía en algunas instituciones educativas (Brasó y Torrebadella, 2018).

A partir de 1894 el deporte fue considerado como un importante medio educativo, que junto a los ejercicios gimnásticos completaron los programas de la educación física en algunos institutos de segunda enseñanza.

El encauzar una buena educación de la infancia con la debida orientación y dirección de los juegos corporales fue una de las preocupaciones pedagógicas. Así lo manifestaban voces como David Ferrer (1900) o Félix Martí Alpera (1900) que trataban sobre cómo debían ser los juegos en los niños. En este punto, hay que considerar, también, las demandas para dotar a las populosas ciudades de campos deportivos y de recreo (Camiñas, 1913; G-Soler, 1906; Marial, 1906; Masferrer, 1902).

El deporte preferido en España fue el fútbol. Como ya se ha citado, el fútbol y el deporte en general) estuvo protegido por las congregaciones educativas religiosas y por la aprobación de significativos mandatarios de la Iglesia (Sardá, 1908; Torras, 1910; Vuillermet, 1925). Del mismo modo, el deporte a la vez que estaba impulsado por las sociedades deportivas católicas en toda Europa (Francia, Inglaterra, Alemania, Italia....), recibía la bendición vaticana del Papa Pío X (Blanco, 1930).

La visión educativa del deporte venía también correspondida por los informes pedagógicos que se desprendían de los viajes de estudios (Álvarez Santullano, 1908; Homs, 1908). No obstante, la susceptibilidad de la iniciación deportiva escolar dependía, considerablemente, de la posibilidad de disponer de campos de juego y de grandes espacios al aire libre. Aun así, todavía había quien defendía, a nivel pedagógico, una mal entendida gimnástica deAmorós (Bembo, 1912ab), que podía complementarse con el deporte (Torrebadella-Flix, 2017a).

La aceptación del deporte escolar fue directamente proporcional al grado de excelencia y categoría de los colegios de enseñanza. Digamos, entonces, que el deporte se fue introduciendo como medio de educación física en la mayoría de los colegios religiosos: Escolapios, Salesianos, Hermanos Maristas, como también en algunos de los centros de la Escuela Nueva, sirviendo de ejemplo el basket-ball y el hockey en la escuela Vallparadis de Terrassa (1910-1914) (Llobera, 1934).

Esto sucedía en una época en que España se encontraba al margen del movimiento olímpico internacional, del cual la misma ILE no le interesó participar (Otero, 1996). Eran momentos en los que algunas voces declaraban que «España ha hecho el triste papel de no mandar ni un solo individuo y no por cierto de poseerlos, quedando por debajo de la misma Turquía» (Los Juegos Olímpicos, 1908, p. 325). Como mencionaba el Marqués de Villamejor «Queno se repita más la vergüenza de 
ser España la única nación del mundo que no concurrió a las pasadas Olimpiadas» (Sanz, 1913, p. 4). Hay que destacar, pues, que a partir de esta fecha se organizó un movimiento nacional pro deporte que fue impulsado desde el influyente el Sindicato de Periodistas Deportivos de Barcelona, liderado por promotores del deporte como Narciso Masferrer o José Elias Juncosa, con el apoyo, en Madrid, de Ricardo Ruiz Ferry (Torrebadella-Flix, 2015; Torrebadella \& Arrechea, 2017a).

Desde los sectores sanitarios (médicos e higienistas), se advertía que la práctica deportiva debía iniciarse al llegar a la adolescencia. Por otro lado, había posiciones intermedias que aconsejaban que a partir de la adolescencia fuera conveniente el complemento de la gimnástica metódica con el deporte, para compensar de este modo los desequilibrios musculares que producía la especialización deportiva. Asimismo, una educación física estructurada a partir de la gimnasia sueca se concebía como la base de preparación de las prácticas deportivas.

Además, hay que señalar durante este período la adopción de todo un conjunto de medidas institucionales dirigidas a contrarrestar los efectos sociales por la depauperación de la clase obrera. Las intenciones de estas medidas se concentraron en el campo higiénico-pedagógico de la infancia con la puesta en marcha de centros de recuperación infantil, colonias de vacaciones, escuelas al aire libre, cantinas escolares, etc. (Galera, 2015a).

En estos años, los juegos deportivos tenían ya recursos didácticos de un importante valor pedagógico. Así los presentaba Ketty Jentzer (1921), profesora del Instituto J. J. Rousseau de Ginebra, en Juegos educativos al aire libre yen casa. Entre los juegos, que podríamos llamar «pre-deportivos», se encontraban el balón a mano, volley-ball, balón a cesta, pelota a volea, balón prisionero, fútbol al límite..., es decir, juegos entre bandos (de oposición-colaboración) con reglas y condiciones de práctica simplificadas para su introducción en el entorno escolar. De todos modos, estos juegos no podían ser aplicados en las escuelas por la falta de espacios adecuados, razón por la cual se pedían campos de juegos públicos. Esta fue una reiterada petición en ciudades como Barcelona, lugar en el que se concentraba un importante asociacionismo deportivo infantil (Ajuntament de Barcelona, 1920; Masferrer, 1918; R. C. M., 1923).

En este período, el conflicto higiénico-pedagógico de la práctica deportiva en edades infantiles aún continuaba. Desde los sectores médicos e higiénicos se aconsejaba el deporte a partir de la adolescencia; en cambio, otros, menos radicales, recomendaban en la adolescencia las prácticas deportivas, complementadas con ejercicios gimnásticos para la compensación de los desequilibrios musculares del deporte (Torrebadella, 2012)

La popularización del deporte a partir de los años veinte, sobre todo a raíz de la primera participación española en unos Juegos Olímpicos (los de Amberes de 1920) y el boom futbolístico que provoco la medalla de plata de la Selección española, aún extendió con más fuerza los concursos infantiles de toda índole. Estos concursos o campeonatos pueriles, aunque su práctica no fuese fomentada por los sectores educativos, sino más bien por las asociaciones deportivas locales, promovían una amplia campaña de promoción educativa de los nuevos valores del deporte. Por consiguiente, el deporte estaba calando profundamente en el imaginario colectivo, contribuyendo a forjar el mito de la pedagogía deportiva, y que ensalzaban autores como Elias $(1916,1917)$ y el mismo Pierre de Coubertin(1925).

Al llegar a los años treinta, la promoción de las figuras deportivas (los ases del deporte) había encajado perfectamente en el imaginario infantil. Especialmente los cuentos deportivos y las colecciones de cromos eran el producto estrella que se encargaba de acrecentar las leyendas y mitos de los héroes del deporte nacional. En esta coyuntura social, y cuando el deporte espectáculo de masas estaba alcanzando un alto nivel de popularidad una la difusión periodística especializada $(\mathrm{Pu}-$ jadas \& Santacana, 2001, 2003), se hacía prácticamente imposibleignorar el deporte en la educación física escolar. Así, manuales de texto para el profesor, como la obra de Miguel Casals (1931), acercaban el deporte (natación, carreras, tenis voleibol, básquet, fútbol, excursionismo, esquí...) al entorno escolar.
Aquí también hay que situar importantes voces críticas en cuanto a la organización escolar de la educación física; una de estas provino del capitán José Hermosa (1931), que desde la Escuela Central de Gimnasia de Toledo se encargó de difundir y orientar el deporte escolar (Torrebadella, 2013a; Torrebadella \& Ticó, 2014).

La aceptación social y popular del deporte, que había nacido del ideal del amateurismo y del fair play, rápidamente se transfiguró en dispositivos de comercialización y consumo. El deporte se había convertido un rentable negocio, no para los que lo practicaban, sino para los verdaderos promotores, que comercializaban con el capital corporal (Barbero, 2005) desde la nueva industria deportiva. De aquí que surgiera una incentivada democratización de la práctica deportiva, no solamente por un interés simbólico en las luchas nacionales, sino también por los intereses económicos de la explotación comercial. Y aquí habría que ubicar tanto los productos propios o inherentes a la práctica deportiva, como aquellos que podían ser indirecta o imaginariamente asociados a la marca deportiva. El deporte era mucho más que deporte y se había convertido en un medio para alcanzar otros fines, que poco tenían que ver con la salud y los inmaculados y vaticinados valores pedagógicos.

Sobre el paradigma que acabamos de describir, las iniciativas privadas sobre el deporte incentivaron la presencia de políticas hacia la promoción; dicho de otro modo, se impulsaron las primeras tentativas hacia la dirección y control administrativo e institucional del deporte como bien de interés público y nacional.

Desde 1894 hasta 1936 el deporte participó de una crisis ideológica y epistemológica, que en el campo conceptual de la higiene y de la educación física opuso sus resistencias, con lo cual el deporte versus la educación física participó de las siguientes consideraciones:

- La insistencia en destacar el valor deporte como un medio más de educación física y como un poderoso medio en la educación moral y del carácter de la juventud.

- La preocupación en diferenciar al deporte como un sistema educativo, del deporte visto como espectáculo.

- El enfrentamiento de aquellos que trataban demostrar al deporte como una expresión antihigiénica, competitiva, violenta y salvaje, con aquellos que lo consideraron como instrumento de salud y de regeneración física.

- La prescripción de la gimnasia educativa como base y preparación para los deportes y la visión de los deportes como complemento de la gimnasia sueca, higiénica o educativa.

- La prohibición del deporte en la educación infantil y el riesgo antes de los 16 y/o 18 años.

- La consideración y orientación de las prácticas deportivas en la mujer.

- La preocupación del estado por dirigir y controlar el movimiento asociativo deportivo y juvenil.

En Cataluña, Josep Elias Juncosa fue uno de los máximos defensores del deporte. Como periodista especializado, se comprometió con el movimiento olímpico y desplegó una intensa campaña divulgativa de los conocimientos y valores del deporte (Torrebadella \& Arrechea, 2017a). Elias (1917) consideraba el deporte como un medio poderoso y suficiente, por sí sólo, de educación física, con la ventaja higiénica del ejercicio al aire libre. Criticaba a la gimnástica por ser poco atractiva, además de carecer de una finalidad inmediata de los diferentes ejercicios. Asimismo, sustentaba la influencia del deporte en la formación del carácter y en la preparación para la vida, con la aportación de altos valores de tipo personal y social. De aquí, que influenciado por la «psicología deportiva» del barón de Coubertin, Elias (1917, p. 3) hablase de «la pronta iniciación del deporte en la escuela, institución responsable de educar en la "pedagogía deportiva». Así proponía la iniciación de la natación a los cinco años, el remo y el boxeo antes de los diez años. A partir de los diez años, se podían introducir los deportes organizados como el foot-ball, el hockey, el basket-ball o el base-ball, teniendo en cuenta una propuesta de condiciones proporcionadas de la pelota, el terreno de juego y la duración de los partidos. A partir de los doce años aconsejaba introducir la esgrima y los deportes atléticos, hasta llegar a 
los dieciséis, momento en que los jóvenes ya podían participar en competiciones escolares o universitarias.

Francisco Cantó, profesor de educación física del Instituto de Castellón, en 1925, defendía la incorporación de los deportes en la educación física. Solamente ponía objeciones a los deportes y ejercicios de fuerza como el boxeo y el lanzamiento de barra, que eran contraindicados en la niñez. El resto de los deportes los consideraba útiles en la niñez y la juventud, pero como sostenían otras autoridades, opinaba que debían combinarse con el sistema de gimnasia sueca de $\mathrm{P}$. H. Ling. Cantó veía en los deportes un poderoso medio de educación física, como base a la regeneración física y moral del hombre y en la restauración y vigor de la raza. Por otro lado, Cantó (1925) señaló que el deporte también era visto como un medio eficaz en la formación del carácter de los jóvenes, no solamente era eficaz porque conquistaba la salud, sino que además alejaba a éstos de los vicios turbios. El deporte era visto, como se ha reiterado una y otra vez, «una escuela de vida».

Los sports individuales, desarrollan y afirman, sobre todo, la personalidad; cada uno lucha para sí para aumentar su fuerza, mostrar su agilidad, saltar más alto, llegar el primero a la meta, vencer antes enlalucha...

En los juegos deportivos colectivos, lo que más se estima es lo que influye en el carácter; lo que les da un valor eminentemente educador. El jugador de pelota, de tennis, de balompié, etc.; debe saber decidir rápidamente, tener la osadía para el ataque, al que es más fuerte; poseer y saber conservar la voluntad de vencer, a pesar de la supremacía del contrario, desestimando las dificultades y sobreponiéndose a la fatiga. La derrota o el fracaso no le descorazona; antes bien le sirve de acicate para perfeccionarse y reemprender pronto la lucha. El sportman, a medida que se fortifica y se endurece, aprende a resistir el dolor y a dominar y aún martirizar sus nervios. Son los sports escuela de vida, mentores de la voluntad, y generadores del carácter (Cantó, 1925, pp. 22-23).

\section{La posición de los detractores al deporte escolar}

\section{Las primeras oposiciones al deporte}

La oposición pedagógica al deporte tuvo varios frentes. Por un lado, había quienes rechazaban el deporte por ser una práctica extranjera, pero también por ser demasiado violenta. Asimismo, había quienes no deseaban abandonar la disciplinada y metódica gimnasia, puesto que tenía una acción directa y controlada sobre el organismo. En todo caso, el deporte podía ser considerado como un complemento a la educación física:

Nuestros niños tienen hoy día muy desdeñados, juegos que fueron nuestro regocijo cuando no se conocían esos más brutales que han venido del extranjero, $\mathrm{y}$ con los cuales se observan aì menudo traumatismos y accidentes que eran antes por completo desconocidos. El juego del salto, el del marro, el de justicias y ladrones, el del toro (sin armas) ... desarrollan una agilidad, soltura y bien proporcionada masa muscular, con un coeficiente de lesiones y responsabilidad morbosa menor que el del criket, liwn-tennis, foot-ball (Pulido, 1907, p. 2).

En resumen: los niños deben ser educados físicamente por los ejercicios físicos de conjunto, por el tiro al blanco y por la gimnasia sueca, utilizando el canto y la música y toda clase de juegos al aire libre, sin que degeneren en deportes, y sólo para casos especiales, y como aplicaciones determinadas, debe enseñárseles las gimnasias especiales, como el boxeo, la esgrima y la natación, complemento de la educación física general (Z., 1907, p. 3).

Como ya se ha mencionado, en 1913, cuando se debatía la participación española en los próximos Juegos Olímpicos de Berlín (Sanz, 1913a), el profesor Marcelo Sanz publicó Ensayo de una higiene deportiva o los deportes ante la higiene. En esta obra se criticaban las aplicaciones de la educación física y las contradicciones higiénicas que presentaban la práctica de los deportes (Sanz, 1913b). Sanz argumentaba que la gimnasia no debía excluir los juegos y, asimismo, los juegos no deberían tampoco sustituir la gimnasia, sino complementarla. Por ello se destacó en la crítica hacia la institucionalización del deporte escolar, cuyo desarrollo no atendía, ni a los preceptos de la higiene, ni a los de la psicología infantil. En la influyente obra de este profesor se delata una constante oposición al deporte (Sanz, 1915, 1932; Sanz \& Escribano, 1915). Sanz no consideró que el deporte fuera un medio de educación física, eso sí, era un pasatiempo o recreo, desprovisto de todo propósito educativo. Observaba en el deporte un desmedido abuso del ejercicio físico, y un objetivo desviado y opuesto a la educación física. En el fondo, erróneamente, el deporte se confundía con una finalidad de la educación física-, pero era considerado como un ejercicio físico en sí mismo, es decir, simplemente una diversión al servicio de la vanagloria, que busca un interés particular, sin atender a una utilidad social. Véase que se comentaba sobre el deporte infantil en la prensa gráfica de la época:

La afición a los juegos deportivos que antes constituían la distracción de la adolescencia, va cundiendo también entre los niños, y ya son muchas las sociedades que se han constituido en distintas poblaciones de España, cuyos socios no han cumplido los quince años. (...)

El foot-ball, por ejemplo, no es, sin duda, de los que pueden favorecer más eficazmente el desarrollo de los niños. Es juego demasiado brusco y agitado, demasiado propicio a incidentes peligrosos, para que los pequeños jugadores se entreguen a él sin limitaciones deningún género.

Como se juega entre la juventud no debe jugarse entre niños, para evitar que lo que debe constituir un ejercicio conveniente para el desenvolvimiento físico, se convierta en un pugilato peligroso, en el que pueden sufrir lesiónese lamentar quebrantos de importancia en la salud.

La rapidez con que va cundiendo la afición a los deportes entre la niñez, reviste un aspecto algo alarmante, y no estaría de más que los que tienen el deber de velar por ella procuraran encauzar esta afición por derroteros convenientes y útiles.

Dejar a los niños en amplia libertad para que en sus juegos imiten a los hombres, es muy expuesto, como lo es, sin duda, permitirles que los imiten en otras manifestaciones y costumbres de la vida social (Deportes Infantiles, 1914, p. 1).

\section{Las posiciones en los años veinte}

Después de la I Guerra Mundial, cuando el deporte hegemonizaba las políticas de educación física de los Estados, surgieron las opiniones refractarias al lobby deportivo. Si bien la prensa especializada difundía una idealización deportiva de la sociedad, la realidad del deporte en España era puesta en duda por destacados portavoces. Con el hándicap de una nula política deportiva gubernamental, un regeneracionismo tardío no dejaba de evocar las ventajas productivas (individuales y colectivas) de los deportes y su contemplación en una educación física nacional. Este modelo de un deporte de ludus pro patria fue cuestionado cuando se minusvaloraba, por ejemplo, la misma participación de España en los Juegos Olímpicos (Torrebadella \& Arrechea, 2016, 2017b).

En estos momentos, el Dr. César Juarros (1919) puso en crisis ideológica las máximas del modelo deportivo, especialmente cuando se pretendía argumentar que el deporte podía servir como medio de educación física. Para Juarros (1925), al igual que el profesor Sanz, el deporte no educaba de ningún modo y, por lo tanto, no se podía incluir en la educación física. Hay que destacar que Juarros fue la persona más refractaria al deporte escolar, pero también a los propósitos del movimiento olímpico. Sus opiniones se hacían sentir durante la Dictadura de Primo de Rivera, período en que las instancias militares trataron de ejercer un absoluto control del asociacionismo y de su orientación (Quiroga, 2004, 2008).

La obsesión del récord de la marca, del campeonato, es un sentimiento que a toda costa debe evitarse en el alma del niño. Sus riesgos son tres: Narcisismo, parasitismo y desinteresamiento. [...] Por otra parte, olimpismo equivale a especialización, es decir, a predominio de determinadas masas musculares. Predominio traduce desequilibrio; desequilibrio, enfermedad. El olímpico supone 
una deformación del tipo humano. Se obtiene la ventaja a cambio de producir un defecto, una desviación.

Uno de los mayores enemigos de las nuevas generaciones españolas, es el olimpismo como el deporte; totalmente distintos ambos de la auténtica educación física (Juarros, 1925, pp. 136-137).

También se hacía sentir la influyente posición del profesor Dr. Tissié, cuando advertía sobre los peligros del deporte y, en especial al fatigoso y violento juego football, como medio de educación física escolar; una posición que advertían prácticamente todos los médicos de la época (Vives, 1920). Para evitar todo exceso y concertar un orgánico desarrollo fisiológico y cognitivo, Tissié proponía unas fases. La primera consistía en los «juegos infantiles elementales» (de 4 a 7 años), la siguiente en los «juegos intensivos» (de 7 a 12 años): «El juego deja de ser individual, está presidido por una organización con reglas sencillas, se torna en colectivo, la necesidad de asociación se hace sentin» (Vives, 1920, p. 288). Así, por ejemplo, proponía el juego del marro. En una tercera proponía los ejercicios deportivos o «deportes atenuados» (de los 13 a los 18 años), con reglas y elementos modificados para su fácil comprensión y adaptación fisiológica. Y finalmente, a partir de los 18 años, cuando se ha completado el desarrollo fisiológico, ya no habría inconveniente para la práctica de los deportes propiamente dichos.

Otro profesor español, César Emilio Porras (1925) se ocupaba de las manifestaciones pseudodeportivas en la educación física infantil, manifestando que el niño no podía practicar el deporte porque consistía en el juego del adulto. Argumentaba que la educación física del niño no era el deporte, sino la gimnasia y los juegos. El deporte infantil se ponía en contra de la propia educación física. No obstante, ofrecía «una posibilidad de hacer las cosas bien, y es reducir el deporte a juego infantil, adaptando reglamentos y normando la intensidad del ejercicio en forma adecuada a la capacidad y a la educación del niño» (Porras, 1925, p. 32). Porras (1927, p. 6) proponía una de estas adaptaciones que llamaba «deportes infantilizados», en el ejemplo del fútbol consideraba: Campo siempre de hierba y de dimensiones reducidas, balón menos pesado, prohibición de golpes, evitar el exceso de contacto individual con el balón, explicary enseñar la técnica de juego, etc.

Torrebadella (2012) ya destacó el debate impulsado por el francés Georges Hébert (1925) suscitado por la polémica de El Sport contra la educación física; probablemente la obra más crítica de la historia de la educación física. La crítica de Hébert fue contundente y, en relación al deporte escolar puso de relieve aspectos que todavía hoy son de una significativa preocupación. Entre estos, hay que destacar el poco esmero democrático a los intereses y necesidades individuales:

La introducción del sport en la escuela no es reciente. Una primera tentativa tuvo lugar hace muchos años, bajo forma de concurso, y suúnica preocupación durante todo el año fue preparar las pruebas para el concurso. Los débiles y medianos continuaron como el pasado, o sea no haciendo nada. Esto era ya la naciente desviación del sport. Los fuertes no trabajan para perfeccionarse, sino con la idea de ganar un premio y hacer alarde de superioridad; los débiles eran como siempre, sacrificados (Hébert, 1925, p. 104).

En este ensayo Hébert quebrantó los valores del deporte y le achacó toda una serie de problemáticas morales y sociales que atentaban contra la misma educación física. Hébert (1925, p. 103) criticó el «imperio del sport sobre la juventud» y situó al deporte escolar o infantil como una práctica «anti-educativa». Esta obra fue muy bien aceptada en los círculos naturistas y librepensadores, que refractarios al deporte utilizaron el método de gimnasia natural de Hébert.

La influencia de Hébert llegó a ser muy significativa. El pedagogo Rufino Blanco, quien más conocimiento bibliográfico poseía sobre la educación física (Torrebadella, 2014b), participaba de la misma opinión que Juarros, y no aceptaba el deporte bajo un enfoque competitivo, es decir, a expensas de la vanidad por batir el récord o la ambición por sobrepujar las marcas. Blanco citaba (1930, p. 469) que las «efímeras e inútiles vitorias», tienen el riesgo de provocar desequilibrios orgánicos (cardiacos y respiratorios), agotamiento de las energías, traumatismos. Posiciones similares eran compartidas por profesores de educación física, de reconocido criterio, como Marcelo Sanz (1932) y Francisco
Javier Fernández Trapiella (1933).

César Emilio Porras (1925) consideraba que la educación física del niño no podía limitarse al deporte, puesto que debía ser el juego del adulto y, por eso, abolía radicalmente el deporte infantil. Sostenía que la educación física del niño consistía en el juego y en la gimnasia:

Esas manifestaciones pseudodeportivas infantiles son la más clara muestra del alocamiento e inconsciencia del movimiento deportivo actual: es la demostración palmaria de que no solamente ese movimiento no está bien alojado bajo el pabellón de la educación física, sino que es contrario a ella (Porras, 1925, p. 31).

Esta misma posición era defendida por el profesor de educación física Mario Oliveras (1927), que trataba de la gimnasia ortomórfica, como una preparación de base para la adaptación funcional de los deportes. Para este profesor, los juegos deportivos eran, en un último estadio, el complemento directo de la cultura física que se había obtenido mediante una gimnasia ordenada y racional. Los deportes solamente se aconsejaban después de esta debida formación, pudiendo iniciar su práctica a partir del periodo en que los jóvenes estaban en época de estudios universitarios.

Hacer sport sin haber hecho antes gimnasia ortomórfica, es permítasenos la expresión, coger el rábano por las hojas, comenzar por el final, procedimiento irracional y negativo. Decimos negativo porque no sólo no consigue la finalidad propuesta, sino que lejos de aumentar el valor del organismo la aniquila no pocas veces, agotando al propio tiempo sus facultades morales. Cuantísimas veces la natación, el ciclismo, fútbol, carreras a pie, etc., han sido responsables de dilataciones cardíacas, congestiones pulmonares, hemoptisis, etc. (Oliveras, 1927, p. 7)

\section{El conflicto de los años treinta}

Al llegar a los años treinta la popularización del fútbol representaba la hegemonía del deporte espectáculo (Torrebadella-Flix \& NomdedeuRull, 2016), con lo cual este deporte representaba la principal barrera para excitar propagandas de movilización hacia otros deportes susceptibles de uso escolar. Además, se criticaba que el erróneo concepto que se tenía sobre el deporte, «despreciado como un negativo valor de la civilización, o como un producto extranjero que nos hacía parecer ridículos ante nuestro temor al esnobismo, o nuestro añejo afecto al misoneismo», explicaba una de las razones de su tardía llegada y del poco desarrollo alcanzado respecto a otros países (Moya, 1930d, p. 1).

Por otro lado, las retóricas en el ámbito del pensamiento libertario cuestionaron la violencia simbólica y el poder ideológico capitalista y burgués que subyacía en el deporte (Torrebadella, 2016c). Es decir, el deporte era visionado como un atentado a la paz, un dispositivo de movilización de los individuos («meros peleles, máquinas inconscientes») hacia la violencia para enfrentar a las naciones (Olavarrieta, 1930, p. 49): «Es más, llevados al ridículo espíritu de extranjería, hemos olvidado nuestros juegos y ejercicios más castizos, muchos de ellos altamente útiles y elegantes, suplantándoles por deportes bárbaros y antiestéticos, traídos de una y otra parte» (Olavarrieta, 1930, p. 8).

La polémica sobre cómo debía atenderse la educación física escolar estaba en un punto álgido, aspecto que se debatía en entornos especializados, como así sucedía en Cataluña (Torrebadella, 2013b). Precisamente, la cuestión, como muy bien planteaba Sánchez Arias, era ¿gimnasia o deporte? (Rubrik, 1931). Esta cuestión también era abordada por Hernández Coronado (1933) y, desde Valencia, por el Dr. Víctor Manuel Moya, al ocuparse sobre la iniciación deportiva y los peligros del deporte (Moya, 1930abc):

Cuestión de Escuela. Mientras no se eduque al niño físicamente en su más tierna edad, inculcándole la necesidad de una concienzuda preparación de gimnasia racional, convenciéndole de que sin ella no puede ni debe practicar deporte alguno, y ahogando con la disciplina y el convencimiento sus vehementes deseos de notoriedad, poco se conseguirá (Moya, 1930a, p. 1).

Los llamados equipos infantiles de los clubs o centros culturales, constituyen el más absurdo concepto del deporte. La lucha enconada que trae consigo la práctica del Foot-ball (por ejemplo) al mismo 
tiempo que el desmedido ejercicio físico a realizar, redunda perniciosamente sobre el organismo, todavía en fase de formación, ocasionando los intensos trastornos de la hiperfunción (desarrollo excesivo de los miembros y órganos más intensamente ejercitados, lesiones del sistema circulatorio, pulmonar, etcétera) (Moya, 1930c, p. 1).

Así, del mismo modo que el Dr. Moya, y cuando el deporte se estaba instalando como el recurso más fácil y preferible para atender la educación física escolar, Juarros insistía acerca de los peligros de la especialización precoz y recriminaba a los promotores de la educación física y del deporte, advirtiéndoles que:

a) Los padres que consienten a sus hijos hacer deporte antes de cumplidos los dieciséis años les causan daños irreparables.

b) Los educadores que autorizan concursos deportivos antes de dicha edad, además de acreditar su falta de preparación técnica, cometen un ¡delito! a la infancia.

c) Las autoridades que permiten esos concursos faltan a su deber de velar por los intereses de la nación y por la salud pública (Juarros, 1933, p. 15).

En 1934 la revista Atletisme, portavoz de Acción Atlética, entidad que se preocupaba por la difusión del atletismo catalán, criticaba con dureza el deporte infantil. Siguiendo las pautas de Juarros, la editorial doctrinal de la revista consideraba que el deporte infantil era «una aberración», sobre todo, en su estimulación precoz antes de los 16 años y a la formación de las bases físicas y psicológicas de los menores (Editorial, 1934a, 1934b).

El profesorado oficial mantuvo posiciones doctrinales y profesionales muy reivindicativas hacía la solución delos problemas(Torrebadella, 2016a). La apuesta por el deporte educativo estaba ganando la partida a la educación física. El punto culminante se alcanzó cuando en el Nuevo Plan deEstudios del Bachillerato, la educación física dejó de considerarse asignatura y se optó por una opción libre (Rivero y Rodríguez, 2009):

Art. 3. ${ }^{\circ}$ Los juegos y deportes sustituyen a la educación física de los antiguos planes de enseñanza.

No se les considerará como asignatura, y quedan absolutamente prohibidos libros y programas. Será un ejercicio físico que se regulará según las condiciones personales de los alumnos (España, 1934, p. 4).

Al llegar a 1936, la propaganda de los Juegos Olímpicos de Berlín y la Olimpiada Popular de Barcelona llevaron el deporte su máximo nivel de fanatismo ideológico y político, por lo que la problematización subyacente se mezclaba en una coyuntura discursiva compleja. Esta situación que venía a unirse al conflicto, de aquellos que ya se mostraban detractores al deporte, quedó reflejado en el Diccionario de la Pedagogía Labor con la palabra, 'deporte':

No obstante, críticas severas han sido formuladas contra los deportes. Algunos maestros de educación física les acusan de las peores calamidades. Sostienen que los deportes causan el surmenage físico, la dilatación cardíaca, trastornos renales, adelgazamiento, agotamiento general y predisposición a las tuberculosis. (Labor, 1936, p. 856)

Por consiguiente, podemos mencionar que al llegar a 1936 se cerraba una etapa embrionaria en la historia de la institucionalización de la educación física y el deporte escolar. A partir de entonces, la educación física y el deporte escolar entraban en una nueva singladura histórica bajo las directrices de las «disciplinas del Movimiento» o del nuevo régimen político (Galera, 2015b), que utilizó el deporte «como elemento de cohesión nacional» (Pastor, 1997, p. 444) y la educación para cimentar las bases ideológicas de una comunidad imaginada de la nación, que se re-cristianizaba y españoliza en la nueva idea de Hispanidad (Laudo \& Vilanou, 2015). Este discurso también se solapó a la educación física y el deporte escolar al poner en juego la biopolítica juvenil de la Dictadura (Cayuela, 2009) y los campeonatos escolares a través del Frente de Juventudes (Pastor, 1997; Rivero \& Rodríguez, 2009). De aquí se observa todo el legado de un deporte escolar que del postfranquismo (transición democrática) ha mantenido hasta nuestros días. Si bien parece quela educación física ha cambiado ideológicamente en los cauces dela democracia, siguesuministrandola gubernamentalidad de la infancia hacia el encauzamiento de un modelo educativo (y de adoctrinamiento) para deportivizar (disciplina corporal-deportiva) a toda una sociedad; en otras palabras, «la necesidad de controlar a las poblaciones para asegurarse la productividad» (Barbero, 1993, p. 11).

\section{Sobre una disertación crítica imprescindible}

En la coyuntura internacional de entreguerras del siglo XX, la utilización política del deporte como motor social de la movilización de la juventud fue configurada como elemento coadyuvante para la construcción de nacional de los estados (Hobsbawm, 1991). La base de esta política se institucionaliza en el régimen escolar de una educación que toma prestado el modelo anglosajón de una formación a través del deporte. En este contexto, se asientan unos usos del deporte escolar, convirtiéndose el cuerpo de la infancia y de la adolescencia en objeto de políticas intervencionistas de dominación social. Como cita Miguel Vicente (2004), no podemos hablar de la construcción social del deporte y de nuestros cuerpos sin conocer y valorar su impacto histórico en el proceso de los regímenes escolares de la infancia y la adolescencia.

En España, el deporte en edad escolar tuvo su primera fase de institucionalización curricular a partir de los años veinte del siglo pasado. Su presencia fue empujada por la coyuntura internacional de expansión del deporte, pero también apareció para satisfacer los intereses quiméricos deunametáfora regeneracionista (Rivero, 2005; Torrebadella, 2014b), en cuya esencia subyacía una política de nacionalización española, diseñada por la monarquía y la dictadura de Primo de Rivera (Quiroga, 2008). El cambio de orientación política con el advenimiento dela II República desencadenó un rico y variado asociacionismo infantil y juvenil, entre cuyas iniciativas localizamos las primeras competiciones escolares propiamente dichas.

El deporte escolar o infantil es la base de la pirámide deportiva contemporánea y blanco económico del capitalismo neoliberal. Y desde hace decenios, la educación de la infancia es estimulada a través de dispositivos disciplinarios de carácter competitivo. De aquí viene que mayoría de los juegos corporales suelen tener una componente agonística simbólica importante, que opera como dispositivo y determina conductas. El poder simbólico del deporte escolar, siguiendo a Bourdieu se presenta como un poder invisible que se cultiva con la complicidad de todos, tanto los que lo sufren como los que lo ejercen (Bourdieu, 2001). Se trata aquí de la ficción de los manipulados valores del deporte, o de «la beatificación de virtudes moralizadoras y normalizadoras», como cita Miguel Vicente (2010, p. 83). Unos valores que constituidos bajo el mito del deporte educativo construyen subjetividades y manipulan conciencias colectivas. Tanto es así, que asistimos a una educación física deportivizada (a una escuela deportivizada y una sociedad deportivizada), en donde el deporte ha determinado la ideología profesional de la materia (Barbero, 2005; Vicente, 2006).

Es muy difícil escapar hoy de la influencia mediatizada del deporte (Perelman, 2014). Sus tentáculos se incrustan en el currículo educativo (Arnold, 2000) y sobre los individuos tienden a conformar el carácter de una sociedad agresivamente competitiva. El estilo de vida deportivo se aprovecha del campo psicológico de las emociones y proyecta fantasías cuya finalidad no es la de hacernos más felices, sino la de precipitarnos irreflexivamente en el consumo(Barbero, 2006). Como práctica social el deporte nunca ha sido limpio, puesto que ha utilizado al hombre (a la ciudadanía) para proyectar las disputas entre los estados y las naciones (Corriente \& Montero, 2011).

Hoy el mito de la educación deportiva impele la práctica de estimuladores discursos que invitan a construir sobre valores éticos una idealizada sociedad en la disyuntiva del fair-play (Durán, 2013). El currículo de educación física en educación primaria de la LOMCE permite el desarrollo del deporte (Muñoz Díaz, 2014). No obstante, no es interpretado de igual modo por todas las comunidades autónomas, donde aparecen diferencias substanciales (Julián, Abarca-Sos, Zaragoza, \& Aibar, 2016; Méndez, Fernández-Río, Méndez, \& Prieto, 2015). Si en algunas comunidades autónomas se combaten los excesos de deportivización y de competitividad, como sucede en Cataluña 
(Departament d'Ensenyament, 2015), en cambio, en otras comunidades, sucede todo lo contrario y se fomenta el deporte como un eje medular de la educación. Así sucede en la Comunidad Autónoma de Madrid, al permitir que la educación física se convierta en una «iniciación a la competición» y la posibilidad de concebir un completo «programa de actividades deportivas». Así el currículo establece que:

La Educación Física es importante para la adquisición de hábitos de vida activa y saludable en los primeros años de escolarización. Entre estos hábitos, necesarios para alcanzar un desarrollo físico de carácter integral, el de la práctica deportiva tiene especial relevancia. El deporte, tanto individual como en equipo, ayuda, además, a fomentar la disciplina, la fuerza de voluntad, el espíritu de superación y colaboración y el respeto a las normas y reglas del juego. Los centros escolares fomentarán la actividad física y la práctica deportiva en las clases de Educación Física y en las horas de recreo (Consejería de Educación Juventud y Deporte, 2014, p. 11).

El juego espontaineo y el reglado tienen un lugar importante en el aprendizaje y configuran una metodologiìa que favorece el trabajo libre al principio para ir atendiendo a normas y reglas cada vez maìs elaboradas que constituyen el fundamento del deporte. (...) La praìctica deportiva contribuye a la educacioìn de la responsabilidad y de la autonomiìa personal, desarrolla la confianza en uno mismo y la fuerza de voluntad, fomenta el valor del esfuerzo y de la superacioìn personal, desarrolla el espiìritu de colaboracioìn y ensenPa a respetar y valorar las reglas del juego (Consejería de Educación Juventud y Deporte, 2014, p. 72).

La competición enseña a jugar limpio, a respetar las reglas del juego y las decisiones de jueces y árbitros, a superarse, a colaborar con los compañeros de equipo y a respetar al rival. Aprender a competir y a extraer de la competición enseñanzas para su vida es importante para la formación de los alumnos (Consejería de Educación Juventud y Deporte, 2014, p. 75).

Es sabido y extendido en muchos docentes en Educación Física la preocupación existente a la hora de realizar actividades físico-deportivas, especialmente aquellas que requieren de participación grupal, pues existen y se generan frecuentemente conflictos y problemas relativos a: exceso de individualismo, exceso de competitividad, falta de respeto entre iguales, poco nivel de socialización, rechazo y exclusión entre iguales por el nivel de condición física y de adquisición de habilidades y destrezas motrices -y la correspondiente desconfianza y frustración que ello conlleva-.

Se hace necesario, por tanto, conocer, fomentar, gestionar y poner en práctica técnicas y actividades hacia la resolución de estos conflictos que generen participación, entusiasmo, complicidad, confianza e integración en el alumnado. Sobre este propósito ya se han presentado iniciativas entorno a una Didáctica Crítica de la educación física (Vicente, 2016), que frecuentemente pasa por un aprendizaje cooperativo, comprensivo y afectivo que desescolarice la educación física de sus códigos disciplinares. Aquí cabe, por ejemplo, el denominado Enfoque de Coopedagogía (Velázquez Callado, 2010) y otros modelos centrados en la cooperación (Fernández-Río, 2017; Fernández-Río \& MéndezGiménez, 2016)

Por otro lado, los contenidos relacionados en el ámbito de la expresión corporal se presentan como alternativas críticas al exceso de deportivización escolar e invitan a una educación sostenible y afectiva con los entornos y las distintas hermenéuticas de la corporalidad (Planella, 2006). Sin embargo, comprobamos como las inercias en la precoz especialización deportiva ya han superado a los progenitores y a las federaciones, ahora es la propia escuela la que se presta a colaborar en el dispositivo deportivo, a través las quimeras saludables, de los héroes y valores del deporte.

\section{Conclusiones}

El deporte apareció como un nuevo sistema de educación física y creó su propia escuela, enfrentándose a las otras escuelas que dominaban el mosaico de la educación física en Europa. El éxito se consolidó a través del discurso construido por el olimpismo internacional; un movi- miento burgués cuyas intenciones no eran otras que las de un control social de la producción. Por esto, el deporte fue aceptado rápidamente, por todo el mundo, porque estaba íntimamente ligado a la recreaciónal descanso después del trabajo, para luego trabajar con mayor eficacia y rendimiento-y a la libertad asociativa de su práctica. Así fue como el deporte eclipsó al resto de escuelas gimnásticas, sencillamente porque no venía impuesto por una autoridad, sino su práctica dependía de un contrato social aceptado por las ansias de progreso de la comunidad. Esto también suponía aceptar la imbricación del deporte en las transformaciones productivas y sociales del momento y aceptar su credo capitalista: competitividad, tecnificación, especialización, profesionalismo, espectáculo, mercancía de consumo...

Ya democratizado, el deporte se organizó institucionalmente a todos los niveles, mostrando sus matices y diversificaciones, capturando caracteres ideológicos muy dispares. Por tanto, el debate suscitado por el enfrentamiento entre partidarios y detractores del deporte se manifestaba en la pragmática de concebir una educación física imbricada de argumentos pedagógicos, higiénicos, morales y propuestas didácticas. Así, pues, tanto partidarios como detractores, con argumentos de hondo calado histórico, ofrecían su posicionamiento justificando las bondades o prejuicios del deporte.

En el primer tercio del siglo XX, Josep Elias, Francisco Cantó y Emilio César Porras, entre otros autores de renombre, mostraron sus motivos valedores y partidistas del sí al deporte. Así, realzaron el deporte, con el permiso de los sectores médicos e higiénicos, como un poderoso recurso educativo, medio configurador del carácter de los jóvenes, que en definitiva resultaba una auténtica «escuela de vida».

Los detractores del deporte, con nombres de relieve, como Marcelo Sanz, el Dr. César Juarros, e incluso el célebre Georges Hébert, alegan una infinidad de calamidades físicas y fisiológicas y, concluían que su finalidad no podía ser educativa, al proclamar el rendimiento desmedido, la obsesión por el récord y el campeonismo, entre otros argumentos difamadores y opositores al deporte.

No hay duda, que hoy estos conflictos siguen afectando a la educación física, con lo cual parte del profesorado se enrola hacia giros didácticos en el marco de la una didáctica crítica y trata de generar éticas a contracorriente de la cultura deportiva (y económica) dominante.

Por último, cabe matizar como autocrítica, que ante la dificultad en desarrollar este campo de investigación en un solo artículo y dada la complejidad y extensión del mismo, sería conveniente la atención de varios artículos referidos a diferentes etapas históricas. Solamente asíse alcanzaría un rigor y profundidad sobre las particularidades que aquí se han suscitado. Es necesario, por lo tanto, abrir un estudio más pormenorizado con nuevas fuentes primarias que posibiliten las diversas líneas de investigación posibles. Con ello, efectivamente, se ampliaría el conocimiento de la historia del deporte y de la Educación Física actual.

\section{Referencias}

Ajuntament de Barcelona (1920). Els jardins dels infants. Barcelona: Ajuntament de Barcelona. Comissió de Cultura.

Alfonso, E. (1925). Cómo cura la medicina natural. Divulgación teórica y práctica del método higio-terapéutico, naturista o hipocrático ( $3^{\mathrm{a}}$ ed.) Madrid: Editorial Pueyo.

Álvarez Santullano, L. (1908, 1 de mayo). Memoria acerca de la educación física en las escuelas de Francia y Bélgica. La Escuela Moderna, p. 394-397.

Arnold, P. J. (2000). Educación física, movimiento y currículum. Madrid: Morata.

Barbero, J. I. (1996). Cultura profesional y currículum (oculto) en educación física. Reflexiones sobre las (im) posibilidades del cambio. Revista de educación, 311, 13-49.

Barbero, J. I. (2005). La escolarización del cuerpo: reflexiones en torno a la levedad de los valores del capital 'cuerpo' en educación física. Revista Iberoamericana de educación, 39, 25-51.

Barbero, J. I. (2006). Deporte y cultura: de la modernidad a los discursos posmodernos del cuerpo». Educación Física y Deporte. Universidad de Antioquía, 25(1), 69-93.

Barbero, J. I. (Ed.) (1993). Materiales de sociología del Deporte. Madrid: La Piqueta.

Bembo, M. (1912a). Historia de la enseñanza: Los niños del Coronel 
Amorós (Manual de Gimnástica pestalozziana). Archivos de Pedagogía y Ciencias Afines, 11(31), 73-89.

Bembo, M. (1912b). Historia de la enseñanza: Los niños del Coronel Amorós (Manual de Gimnástica pestalozziana) (Conclusión). Archivos de Pedagogía y Ciencias Afines, 11(32), 227-269.

Blanco, R. (1930). Teoría de la educación, tomo I. Madrid: Lib. Ed. de Hernando.

Bourdieu, P. (2001). Poder, derecho y clases sociales. Bilbao: Desclée.

Brasó, J., \& Torrebadella, X. (2015a). El joc del 'rescat' en el procés constituent de l'esport contemporani a Catalunya (1920-1926). Aloma: Revista de Psicología, Ciències de l'Educació i de l'Esport, 33(1), 79-91.

Brasó, J., \& Torrebadella, X. (2015b). «El marro», un juego tradicional y popular en la educación física española (1807-1936). Revista Complutense de Educación, 26(3), 697-719.

Camiñas, V. (1913). Terrenos de juego y utilidad de la recreación, en las ciudades de terrenos especiales para los deportes escolares. - Juegos infantiles desde el punto de vista higiénico y educativo. En Primer Congreso Español de Higiene Escolar (pp. 67-71). Barcelona: Imp. de la Viuda de Francisco Badia Centenys.

Cantó, F. (1925). Influencia de los deportes en la educación física. Castellón: Talleres Tipográficos Hijo de J. Armengot.

Casals, M. (1931). Gimnasia, juegos y deportes. Manual de educación física recreativa. Barcelona: Casals.

Cayuela, S. (2009). El nacimiento de la biopolítica franquista. La invención del «homo patiens». Isegoría, 40, 273-288.

Consejería de Educación Juventud y Deporte (2014). DECRETO 89/ 2014, de 24 de julio, del Consejo de Gobierno, por el que se establece para la Comunidad de Madrid el Currículo de la Educación Primaria. Boletín Oficial de la Comunidad de Madrid, 25 de julio de 2014, ${ }^{\circ}$ 175, p. $10-89$.

Corriente F., \& Montero, J. (2011). Citius, Altius, Fortius: El libro negro del deporte. Logroño: Pepitas de Calabaza.

Coubertin, P. (1925). Lecciones de pedagogía deportiva. Presentadas en el Instituto Olímpico de Lausana. La Escuela Moderna, 408, 695702 .

Departament d'Ensenyament (2015). Disposicions. DECRET 119/2015, de 23 de juny, d'ordenació dels ensenyaments de l'educació primària. Diari Oficial de la Generalitat de Catalunya, 26 de juny de 2015, ${ }^{\circ}$ 6900, p. 1-136.

Deportes Infantiles (1914, 11 de febrero). Mundo Gráfico, p. 5.

Durán, J. (2013). Ética de la competición deportiva: valores y contravalores del deporte competitivo. Materiales para la Historia del Deporte, 11, 89-115.

Editorial (1934a, 1 de enero). Esport infantil?..., No!!, Atletisme, pp. 46.

Editorial (1934b, 1 de febrero). Més, encara, a propósit de l'esport infantil. Atletisme, pp. 5-6.

Elias, J. (1917). Pedagogía esportiva (acabament). Quaderns d'Estudi, 1(4), 307-313.

España (1934, 29 de agosto). Nuevo Plan de Estudios del Bachillerato, Luz, p. 4.

Fernández Trapiella, F. J. (1933). Ciencia y arte de la educación física. Toledo: Imp. de Rodríguez y $\mathrm{C}^{\mathrm{a}}$.

Fernández, A. (1971). Sport y deporte. Compuestos y derivados, Citius, Altius, Fortius, 13, 291-307.

Fernández-Río, J. (2017). El Ciclo del Aprendizaje Cooperativo: una guía para implementar de manera efectiva el aprendizaje cooperativo en educación física. Retos. Nuevas Tendencias en Educación Física, Deporte y Recreación, 32, 264-269

Fernández-Rio, J., \& Méndez-Giménez, A. (2016). El aprendizaje cooperativo: Modelo pedagógico para Educación Física. Retos. Nuevas Tendencias en Educación Física, Deporte y Recreación, 29, 201206.

Ferrer, D. (1900, 10 de junio). Lo que deben ser los juegos en los niños. Los Deportes, pp. 355-356.

G.-Soler, M. (1906, 13 de septiembre). Parques deportivos. El Mundo Deportivo, p. 2.

Galera, A. D. (2015a). Educación física y protección de la infancia en la Restauración (1875-1931). Regulaciones laborales e instituciones complementarias escolares. Cabás, 13, 1-37.

Galera, A. D. (2015b). Las «disciplinas del Movimiento» en la escuela franquista (1936-1975). Cabás, 14, 74-95.

García Fraguas, José E. (1897). Programa ilustrado de advertencias y figuras de actitudes para las prácticas de gimnasia higiénica, sports, juegos y ejercicios medicinales..., Madrid: Biblioteca de la «Regeneración Física».

$-410$
Hébert, G. (1925). El sport contra la educación física. Barcelona: Mercantil.

Hermosa, J. (1931, 19 de noviembre). España, a la Olimpiada. Un voto en contra. $\mathrm{La} \mathrm{Voz}, \mathrm{p} .7$.

Hernández Coronado, R. (1933, 25 de octubre). ¿La educación física del niño es un camelo? Luz -Diario de la República-, p. 14

Hobsbawm, E. J. (1991). Naciones y nacionalismos desde 1780. Barcelona: Crítica.

Homs, E. (1908, 27 de junio). Un partido de foot-ball-Rugby. La Cataluña, pp. 405-406.

Jentzer, K. (1921). Juegos educativos al aire libre y en casa. Cien descripciones ilustradas con diagramas. Madrid: Ed. Francisco Beltrán Librería Española y Extranjera.

Juarros, C. (1919, 15 de junio). Los deportes como causa de enfermedad. La Educación Física, 1, p. 15.

Juarros, C. (1925). Normas de educación sexual y física. Madrid: Renacimiento.

Juarros, C. (1933). En pro de la noble educación física: El arte de escoger deporte a los niños. El Campeón, 27, 3-4.

Julián, J. A., Abarca-Sos, A., Zaragoza, J., \& Aibar, A. (2016). Análisis crítico de la propuesta del currículum básico de la LOMCE para la asignatura de Educación Física. Acciones derivadas en la Comunidad Autónoma de Aragón y propuestas de futuro. Retos. Nuevas Tendencias en Educación Física, Deporte y Recreación, 29, 173-181.

Laudo, X., \& Vilanou, C. (2015). Educational discourse in Spain during the early Franco regime (1936-1943): toward a genealogy of doctrine and concepts. Pedagógica Histórica, 51(4), 434-454.

Llobera, P. (1934). El espíritu deportivo de las Escuelas Nuevas. Barcelona: Imp. Antonio Porta.

López Serra, F. (1998). Historia de la educación física de 1876 a 1898. La Institución Libre de Enseñanza. Madrid: Gymnos.

Los Juegos Olímpicos (1908, 31 de julio). Los Deportes, pp. 325-326.

Marial, J. (1906, 6 de diciembre). Campos de sport. El Mundo Deportivo, p. 2.

Martí, F. (1900, 1 de mayo). Lo que deben ser los juegos en los niños», $L a$ Escuela Moderna, pp. 362-368.

Masferrer, N. (1902, 5 de enero). Parques Deportivos. Los Deportes, pp. 4-5.

Masferrer, N. (1918, 19 de noviembre). Del ambiente deportivo. Pasques de Sport. El Mundo Deportivo, p. 1.

Méndez, D., Fernández-Río, J., Méndez, A., \& Prieto, J. A. (2015). Análisis de los currículos autonómicos LOMCE de Educación Física en Educación Primaria. Retos. Nuevas Tendencias en Educación Física, Deporte y Recreación, 28, 15-20.

Moya, V. M. (1930a, 10 de febrero). Peligros del deporte. F. C. Semanario Deportivo, p. 1.

Moya, V. M. (1930b, 13 de enero). Iniciación deportiva. F. C. Semanario Deportivo, p. 1.

Moya, V. M. (1930c, 17 de marzo). Continuación del número 8 (Deporte y salud). F. C. Semanario Deportivo, p. 1.

Moya, V. M. (1930d, 24 de febrero). Concepto del deporte. F. C. Semanario Deportivo, p. 1.

Muñoz Díaz, J. C. (2014). El currículo del área de educación física de Primaria en la LOMCE. Análisis del Real Decreto 126/2014. EmásF. Revista digital de educación física, 27, 24-39.

Olavarrieta, J. B. (1930). La salud por el ejercicio. Ávila: Tip. y Enc. de Senén Martín.

Olivera-Betrán, J., \& Torrebadella-Flix, X. (2015). Del sport al deporte. Una discusión etimológica, semántica y conceptual en la lengua castellana. Revista Internacional de Medicina y Ciencias de la Actividad Física y el Deporte, 15(57), 61-91. http://dx.doi.org/10.15366/ rimcafd2015.57.005

Oliveras, M. (1927). Metodización de la cultura física. Barcelona: Imp. del Sucesor de Enrique Teodoro.

Otero, E. (1996). Las relaciones entre Pierre de Coubertin y Francisco Giner de los Ríos. Revista complutense de Educación, 7(2), 201210.

Pastor, J. L. (1997). El espacio profesional de la educación Física en España: génesis y formación (1883-1961). Alcalá de Henares: Universidad de Alcalá de Henares.

Perelman, M. (2014). La barbarie deportiva. Crítica de una plaga mundial. Barcelona: Virus Editorial.

Piernavieja, M. (1966). Depuerto, deporte, protohistoria de una palabra. Citius, Altius, Fortius, 7, 5-190.

Planella, J. (2006). Cultura, cuerpo y educación. Bilbao: Desclée de Brouwer.

Porras, C. E. (1925). Educación física: Concepto general desde el punto Retos, número 34, 2018 ( $2^{\circ}$ semestre) 
de vista higiénico, de los deportes actuales y su acción benéfica o perjudicial en el desarrollo de la juventud. Madrid: Imp. de la Ciudad Lineal.

Porras, C. E. (1927, 24 de febrero). El niño y el deporte. El Imparcial, p. 6.

Pujadas, X., \& Santacana, C. (2001). La mercantilización del ocio deportivo en España. El caso del fútbol (1900-1928). Historia social, 47, 147-168.

Pujadas, X., \& Santacana, C. (2003). El club deportivo como marco de la sociabilidad en España. Una visión histórica (1850-1975). Hispania. Revista Española de Historia, 214, 505-522.

Pulido, Á. (1907, 14 de febrero). Los juegos de niños. El Mundo Deportivo, p. 2.

Quiroga, A. (2004). 'Los apóstoles de la Patria'. El Ejército como instrumento de nacionalización de masas durante la Dictadura de Primo de Rivera. Mélanges de la Casa de Velázquez, 34(1), 243-272.

Quiroga, A. (2008). Haciendo españoles. La nacionalización de las masas en la Dictadura de Primo de Rivera (1923-1930). Madrid: Centro de Estudios Políticos y Constitucionales.

R. C. M. (1923, 18 de enero). Faltan campos de deportes para nuestros infantiles. La Pelota Semanal, p. 1.

Rivero, A., \& Rodríguez, G. (2009). Los campeonatos escolares en España. Breve síntesis histórica. Materiales para la historia del deporte, 7, 23-34.

Rivero, A. (2005). Deporte y modernización. Sevilla: Wanceulen.

Rubrik (Román Sánchez Arias) (1931, 22 de enero). De educación física. ¿gimnasia o deportes?, $A B C$, p. 50.

San Martín, A. (1889). De los juegos corporales más convenientes en España. El Ateneo. Revista científica, literaria y artística, 3, 53-75.

Sanz, M., \& Escribano, R. (1915). Segundo curso teórico-práctico de educación física. Madrid: Imp. La Enseñanza.

Sanz, M. (1913a, 14 de setiembre). Juegos Olímpicos. Por la patria y por la raza. La Correspondencia de España, p. 4.

Sanz, M. (1913b). Ensayo de una higiene deportiva o los deportes ante la higiene. Madrid: Imp. de «La Correspondencia militar».

Sanz, M. (1915). Manual de Gimnasia higiénica y juegos escolares. Madrid: Est. Tip. de Juan Pérez Torres.

Sanz, M. (1932). Cultura física. Madrid: Manuales «Germen».

Sardá, F. (1908). L’sport católich. Barcelona: Lib. Tip. Católica.

Soler Damians, J. (1936). Assaig d'un pla general d'educació física. Barcelona: Norma.

Tissié, P. (1919). L'éducation physique et la race: santé, travail, longévité Paris: Flammarion.

Torras, J. (1910). L'atletisme cristià carta pastoral amb motiu del sant temps de Quaresma de 1910. Vic: Imp. Anglada.

Torrebadella, X. (2012). El deporte contra la educación física. Un siglo de discusión pedagógica y doctrinal en la educación contemporánea. Movimiento humano, 4, 73-98.

Torrebadella, X. (2013a). Anotaciones al balonmano en el contexto histórico del deporte en España (1900-1939). e-balonmano. Revista de Ciencias del Deporte, 9(2), 115-134.

Torrebadella, X. (2013b). L’Acadèmia d’Educació Física de Catalunya. Un intent per legitimar un espai institucional i doctrinal de l'educació física en la II República. Apunts. Educación Física y Deportes, 114, 23-35.

Torrebadella, X. (2014a). Regeneracionismo e impacto de la crisis de 1898 en la educación física y el deporte español. Arbor, 190 (769) a173. doi: http://dx.doi.org/10.3989/arbor.2014.769n5012

Torrebadella, X. (2014b). Rufino Blanco Sánchez y las fuentes bibliográficas de la educación física y el deporte en España. RICYDE. Revista Internacional de Ciencias del Deporte, 37, 281-284.

Torrebadella, X. (2016a). De la Asociación de Profesores y Profesoras Oficiales de Gimnástica (1891) al Colegio Nacional de Profesores de Educación Física (1948). Un análisis histórico para una crítica del presente. II parte (1901-1948). Revista Española de Educación Física y Deportes, 414, 85-102.

Torrebadella, X. (2016b). España, regeneracionismo y deporte durante la I Guerra Mundial. Athenea Digital. Revista de Pensamiento e Investigación Social, 16(1), 237-261. doi:http://dx.doi.org/10.5565/rev/ athenea.1501

Torrebadella, X. (2016c). Francisco Ferrer Guardia, postmoderno avanzado y precursor de la educación física crítica. Análisis y reflexión para un giro didáctico. Educar, 52(1), 169-191. doi: http://dx.doi.org/ 10.5565/rev/educar.756.

Torrebadella, X. (2017). La militarización de la educación física escolar Análisis de dos imágenes publicadas en la prensa de Barcelona de principios del siglo XX. Historia Social y de la Educación, 6(1), 78-

Retos, número 34, 2018 ( $2^{\circ}$ semestre)
108. doi:10.17583/hse.2017.2393

Torrebadella, X., \& Arrechea, F. (2016). La polémica participación de España en los Juegos Olímpicos de Amberes 1920. Materiales para la Historia del Deporte, 14, 113-138.

Torrebadella, X., \& Arrechea, F. (2017a). Josep Elias i Juncosa el primer «apóstol» del olimpismo y del deporte escolar en España. Ágora para la Educación Física y el Deporte [en prensa]

Torrebadella, X., y Arrechea, F. (2017b). Seguimos insistiendo: ¿Por qué España participó en los Olímpicos de Amberes 1920? Materiales para la Historia del Deporte, 15, 145-168.

Torrebadella, X., y Brasó, J. (2018, en prensa). Los juegos corporales en la educación física del siglo XIX como preludio al deporte moderno en España. Ciencia, Cultura y Deporte

Torrebadella-Flix, X. (2015). Forjando los Juegos Olímpicos de Barcelona: La contribución de Narciso Masferrer y Sala en la configuración del deporte nacional e internacional (1900-1910). Citius, Altius, Fortius, 8(1), 61-103.

Torrebadella-Flix, X. (2017a). Filantropía, educación y fútbol: la obra benéfica de Max Bembo en Barcelona (1907-1922). Revista Internacional de Educación para la justicia social, 6(2), 177-199. https:/ /doi.org/10.15366/riejs2017.6.2.011

Torrebadella-Flix, X. (2017b). La historia de la educación física escolar en España. Una revisión bibliográfica transversal para incitar a una historia social y crítica de la educación física. Espacio, Tiempo y Educación, 4(1), 1-40. http://dx.doi.org/10.14516/ ete.2017.004.001.76

Torrebadella-Flix, X., \& Nomdedeu-Rull, A. (2016). La popularización del fútbol en España. Análisis del fenómeno a través de la literatura especializada del fútbol (1920-1936). Revista General de Información y Documentación, 26(1), 119-146.

Torrebadella-Flix, X. \& Ticó, J. (2014). Notas para la historia del centenario del baloncesto español. Un deporte escolar y popular para ambos sexos (1897-1938). E-Balonmano.com: Revista de Ciencias del Deporte, 10(3), 177-198.

Torrebadella-Flix, X., Olivera-Betrán, J. \& M-Bou, M. (2015). Origin and Institutionalisation of Sports and Gymnastics Associations in Nineteenth-Century Spain (1822-1900). Apunts. Educación Física y Deportes, 119, 7-54. DOI: http://dx.doi.org/10.5672/apunts.20140983.cat.(2015/1).119.01

Torrebadella-Flix, X., Olivera-Betrán, J., \& M-Bou, M. (2017). The origins of football in Spain. From the first press appearance to the constitution of the first clubs (1868-1903). The International Journal of the History of Sport. http://dx.doi.org/10.1080/ 09523367.2017.1365707

Torrebadella-Flix, X., y Vicente-Pedraz, M. (2017). En torno a los orígenes del fútbol como deporte escolar en España (1883-1936). De moda recreativa a dispositivo disciplinario. Educación Física y Ciencia, 19(1), e018. https://doi.org/10.24215/23142561e018

Trapero, M. (1994). Del depuerto medieval al deporte actual, cuestiones semánticas. En García, C., G. Reigosa, C., García, P., Gómez, A., \& Muro, M. A. (Coord.). Congreso sobre el idioma español en el deporte (pp. 79-108). Madrid: Fundación EFE.

Velázquez Callado, C. (Coord.) (2010). Aprendizaje cooperativo en Educación Física. Fundamentos y aplicaciones prácticas. Barcelona: INDE.

Vicente, M. (2004). Cuerpo y contracuerpo: la historicidad de las producciones corporales y el sentido de la Educación Física. Educación Física y Ciencia, 7, 68-86.

Vicente, M. (2006). Arqueología de la Educación Física y otros ensayos. Armenia: Kinesis.

Vicente, M. (2009). La educación física como ideología del poder: la construcción de las creencias pedagógicas en torno las enseñanzas escolares del cuerpo. Revista Educación, 33(2), 109-138.

Vicente, M. (2010). Educación Física e ideología. Creencias pedagógicas y dominación cultural en las enseñanzas escolares del cuerpo. Retos. Nuevas Tendencias en Educación Física, Deporte y Recreación, 17, 76-85.

Vicente, M. (2016). Bases para una didáctica crítica de la educación física. Apunts. Educación Física y Deportes, 123, 76-85. DOI: http:// dx.doi.org/10.5672/apunts.2014-0983.cat.(2016/1).123.09

Vives, J. L. (1920, 1 de mayo). Los libros importantes extranjeros. L'éducation physique et la race». La Escuela Moderna, pp. 282290.

Vuillermet, F. A. (1925). La juventud y los deportes. Madrid: Voluntad.

Wagner, H. (1970). Etiología y concepto de «sport». Citius, Altius, Fortius, $11-12(1$ y 4$), 385-391$.

Z. (1907, 14 de septiembre). Elección de ejercicios físicos. El País, p. 3. 